\title{
AUTOFLUORESCENCE IN THE OOCYSTS OF MARINE AND FRESHWATER FISH COCCIDIA
}

\author{
Angela Davies and Barbara Stewart
}

School of Life Sciences, Faculty of Science, Kingston University, Kingston upon Thames, Surrey KT1 2EE, U.K.

\begin{abstract}
Autofluorescence has been reported as a method for detecting oocysts of Cyclospora cayetanensis in patients with seasonal diarrhoea (Berlin O.G.W., Peter J.B., Gagne C., Conteas C.N., Ash L.R. 1998: Emerg. Inf. Dis. 4: 127-128), although the same technique had been used earlier, for probably the same parasite, in human subjects with prolonged diarrhoea (Long E.G., White E.H., Carmichael W.W., Quinlisk P.M., Raja R., Swisher B.L., Daugharty H., Cohen M.T. 1991: J. Inf. Dis. 164: 199-202; Berlin O.G.W., Novak S.M., Porschen R.K., Long E.G., Stelma G.N., Schaeffer F.W. 1994: Clin. Inf. Dis. 18: 606-609). Autofluorescence has also been utilised to detect Isospora belli oocysts in AIDS patients (Berlin O.G.W., Conteas C.N., Sowerby T.M. 1996: AIDS 10: 442-443) and Cryptosporidium parvum oocysts in human stools (Varea M., Clavel A., Doiz O., Castillo F.J., Rubio M.C., Gómez-Luz R. 1998: Int. J. Parasitol. 28: 1881-1883). To test whether the oocysts of fish coccidia also autofluoresce, and to determine whether this might be of practical value, oocysts of Eimeria sardinae (Thélohan, 1890) Reichenow, 1921, Goussia clupearum (Thélohan, 1894) Labbé, 1896 and Goussia metchnikovi (Laveran, 1897) Dyková et Lom, 1983 were examined.
\end{abstract}

Samples of E. sardinae and G. clupearum were obtained, respectively, from the testes of herring (Clupea harengus L.) and the liver of both herring and mackerel (Scomber scombrus L.). These marine fishes were bought, as required, in a chilled condition from fishmongers local to Kingston, U.K. Samples of spleen from freshwater gudgeon (Gobio gobio L.), with G. metchnikovi, were supplied in distilled water by The Environment Agency, Huntingdon, U.K. Small pieces of unfixed testis, liver and spleen $\left(1 \mathrm{~mm}^{3}\right.$ or less) were squashed separately between a coverslip ( $22 \times 22 \mathrm{~mm}$ ) and glass slide. Tissue squashes were then examined with a Zeiss Axioskop 20 photomicroscope with both phase and fluorescence facilities. For fluorescence, a triple filter purchased from Carl Zeiss, Welwyn Garden City, U.K. was employed. Excitation wavelengths used were $410 \mathrm{~nm}, 505 \mathrm{~nm}$ and $585 \mathrm{~nm}$ (with beamsplitters : $395 \mathrm{~nm}, 485 \mathrm{~nm}$ and $560 \mathrm{~nm}$; and barriers: 460 $\mathrm{nm}, 530 \mathrm{~nm}$ and $610 \mathrm{~nm}$ respectively). Initially, areas of tissue infected with coccidia were located by phase contrast microscopy with a $40 \times$ objective, and photographed; these areas were then examined for autofluorescence at the same magnification or with a $100 \times$ (oil immersion) objective, and photographed again. Later, tissue samples were screened at low power $(3 \times$ and $10 \times$ objectives) to compare the efficiency of phase contrast with fluorescence in locating oocysts.

The appearance of the three fish coccidia with phase contrast is recorded in Figs. 1, 3, 5. Sporulated oocysts of G. metchnikovi were particularly abundant in spleen tissue
(Fig. 5) but those of G. clupearum, and especially E. sardinae, were generally more sparce in liver and testis.

Excitation resulted in intense blue autofluorescence in the oocysts of all three species of fish coccidia (Figs. 2, 4, 6, 7). Sporocysts also autofluoresced blue, but whereas those of $G$. clupearum and G. metchnikovi were readily observed (Figs. 2, $6,7)$, those of E. sardinae were hardly visible within the oocyst (Fig. 4). In liver and spleen samples, some red autofluorescence was also visible surrounding individual and groups of oocysts (Figs. 2, 7). This was presumed to result from host lipofuscin, which is also known to autofluoresce (Herman B. 1998: Fluorescence Microscopy. Second Edition. BIOS Scientific Publishers Limited, Oxford, 170 pp.). Samples on slides gradually lost both their blue and red autofluorescence if kept for longer than about 30 minutes.

When samples were screened at low power using phase and then fluorescence, oocysts from all three species were more readily detected by fluorescence than with phase. This was particularly the case for liver and testis squashes that were lightly infected with $G$. clupearum and $E$. sardinae. Lipofuscin was also easily demonstrated by fluorescence at low power.

Excitation wavelengths between 365-436 nm have been reported to induce violet, green and blue autofluorescence in oocysts of Cryptosporidium, Isospora and Cyclospora, depending on the genus of parasite used and wavelength employed (Varea et al. 1998, op. cit.). Blue autofluorescence has been noted with Isospora oocysts at 330-380 nm (ultraviolet) (Berlin et al. 1996, op.cit.) and with Cyclospora oocysts at $365 \mathrm{~nm}$ (Varea et al. 1998, op. cit.). In the present study, a microscope fitted with a triple filter $(410-585 \mathrm{~nm})$ was employed and therefore it was not possible to pinpoint the excitation wavelength that induced blue autofluorescence in the fish coccidia.

The technique described required no staining or fixation, and at low power, oocysts were more easily detected by fluorescence than by phase. Fluorescence may prove useful therefore for screening fish tissues, and possibly fish gut contents, for oocysts and sporocysts. Fresh fish samples may not be required since aged and preserved specimens of human coccidia are also reported to autofluoresce (Varea et al. 1998, op. cit.). The precise source of autofluorescence in our material has not been identified but some amino acid components of proteins are known to have this property (Herman 1998, op. cit.).

Acknowledgements. We are grateful to Professor S.J. Ball for organising the supply of G. metchnikovi with Dr. P. Belfield of The Environment Agency, Huntingdon. Technical assistance was kindly provided by Mrs. G. Sappal. 

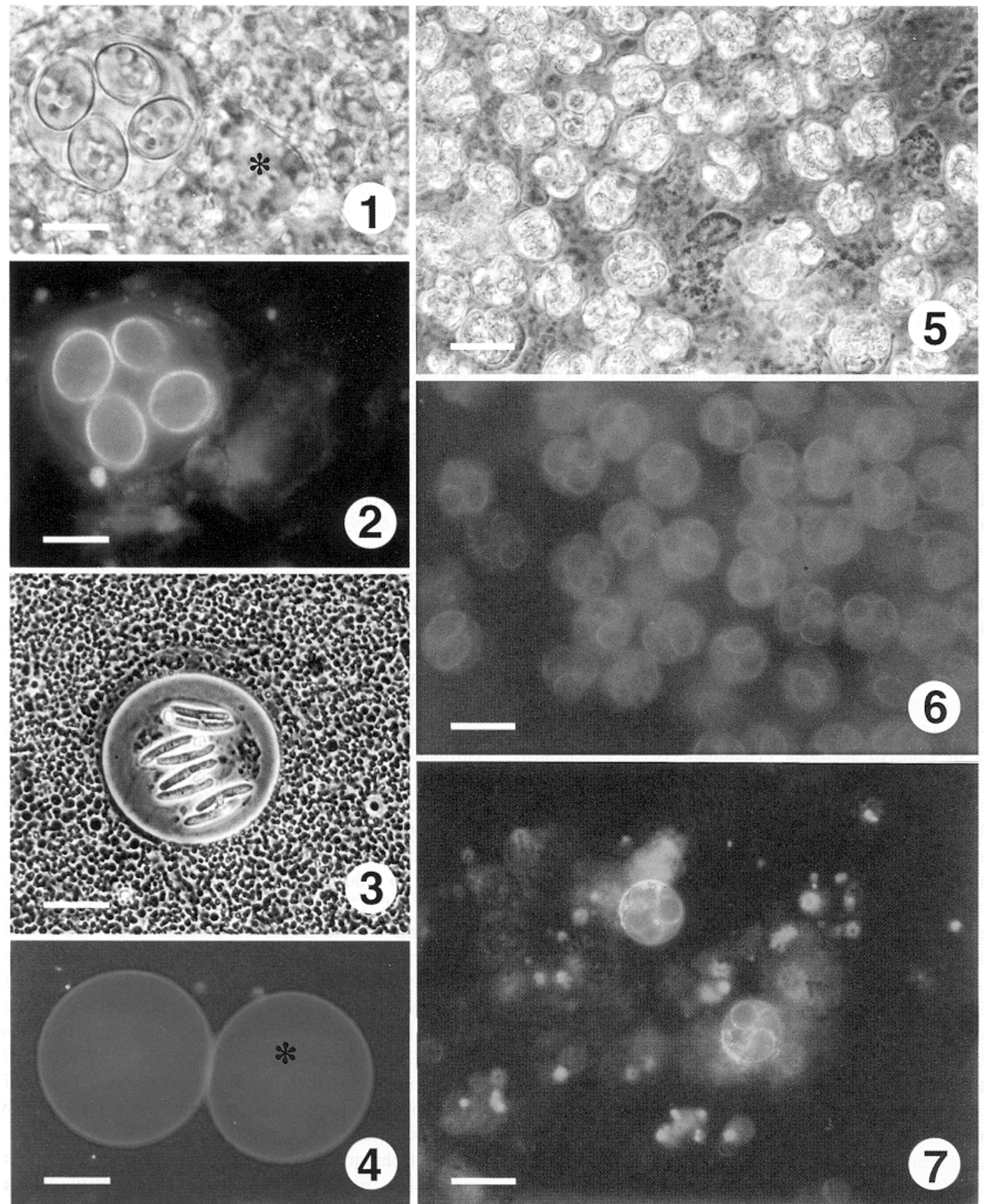

Figs. 1-7. Photomicrographs of unfixed, unstained, fish tissues taken with phase contrast or fluorescence facilities (excitation wavelengths used were $410 \mathrm{~nm}, 505 \mathrm{~nm}$ and $585 \mathrm{~nm}$ ). Fig. 1. Single sporulated oocyst, Goussia clupearum. Asterisk indicates location of some lipofuscin (phase). Fig. 2. Same sporulated oocyst seen in Fig.1. fluorescing blue, with surrounding lipofuscin fluorescing red (autofluorescence). Fig. 3. Single sporulated oocyst, Eimeria sardinae with clearly defined sporozoites and residuum (phase). Fig. 4. Oocysts, E. sardinae with ill-defined sporocysts (asterisk marks one of four within an oocyst); micrograph printed with green enhancement to render sporocysts just visible (autofluorescence). Fig. 5. Large cluster, sporulated oocysts of Goussia metchnikovi (phase). Fig. 6. Oocyst cluster, G. metchnikovi (autofluorescence). Fig. 7. Two oocysts, G. metchnikovi, surrounded by lipofuscin (autofluorescence). Scale bars: Figs. 1, $2=10 \mu \mathrm{m}$; Figs. 3-7 = $20 \mu \mathrm{m}$. 